\title{
Pediatric Nephrology: Highlights for the General Practitioner
}

\author{
Mouin Seikaly, ${ }^{1}$ Sabeen Habib, ${ }^{2}$ Amin J. Barakat, ${ }^{3}$ \\ Jyothsna Gattineni, ${ }^{4}$ Raymond Quigley, ${ }^{4}$ and Dev Desi ${ }^{4}$ \\ ${ }^{1}$ Louisiana State University Health Sciences Center, Pediatric Nephrology, Shreveport, LA, USA \\ ${ }^{2}$ Louisiana State University Health Sciences Center, Shreveport, LA 71115, USA \\ ${ }^{3}$ Georgetown University Medical Center, Washington, DC 20007, USA \\ ${ }^{4}$ University of Texas Southwestern, Dallas, TX 75390, USA \\ Correspondence should be addressed to Mouin Seikaly, mouin.seikaly@childrens.com
}

Received 9 July 2012; Accepted 9 July 2012

Copyright (C) 2012 Mouin Seikaly et al. This is an open access article distributed under the Creative Commons Attribution License, which permits unrestricted use, distribution, and reproduction in any medium, provided the original work is properly cited.

The current special issue is written as a practical guide for the health care providers managing children with kidney diseases. In this issue, the guest editors have emphasized clinical skills, diagnostic procedures, treatment, long-term followup as well as underlying pathophysiology with the general practitioner in mind. Since the call for manuscripts by the journal, we received 27 excellent submissions. We selected 9 papers to include in this special issue. We chose only those that we deemed appropriate to the scope that we outlined for this special issue.

The guest editors who are leading experts in the field of pediatric nephrology did a terrific job writing their designated sections. A. J. Barakat's excellent perspective on presentation of children with renal disease is a practical guideline for referral to the specialist. S. Habib reviews controversies in the management of urinary tract infection. R. Quigley provides a comprehensive yet concrete review about children with chronic kidney disease. J. Gattineni discusses thoroughly the management of children presenting with proteinuria and hematuria. In my section on hypertension, I tried to provide a comprehensive practical guide that can be used in the management of a child with elevated blood pressure.

The nine papers that we selected for publication were outstanding. Y. R. Bhat et al. discuss the antenatal Bartter syndrome in a succinct fashion. D. Morin et al. provide a detailed review on nephrogenic SIADH, and kidney disease and type 2 diabetes mellitus are very well discussed by A. B. Dart et al. The approach to a patient with acute glomerulonephritis is also well covered by T. R. Welch.
On behalf of the contributing authors, we hope that the readership will use our contribution to help them manage children with kidney disease.

\section{Acknowledgment}

Mouin Seikaly, MD, is the Lead Guest Editor for this issue.

Mouin Seikaly

Sabeen Habib

Amin J. Barakat

Jyothsna Gattineni

Raymond Quigley

Dev Desi 


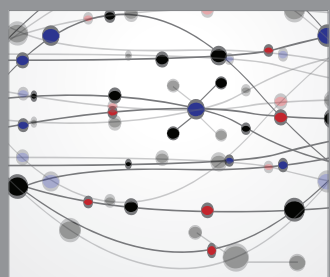

The Scientific World Journal
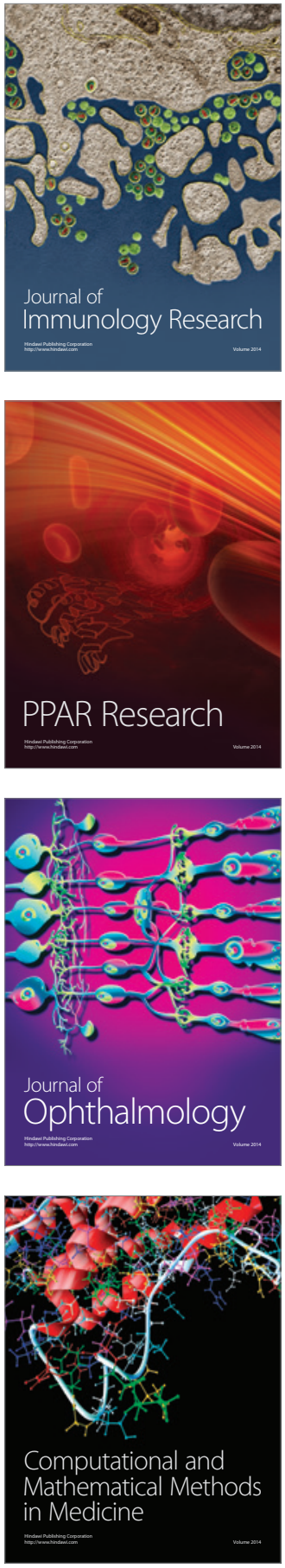

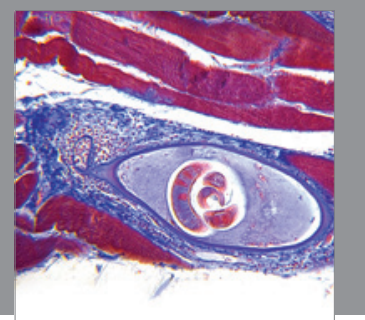

Gastroenterology

Research and Practice
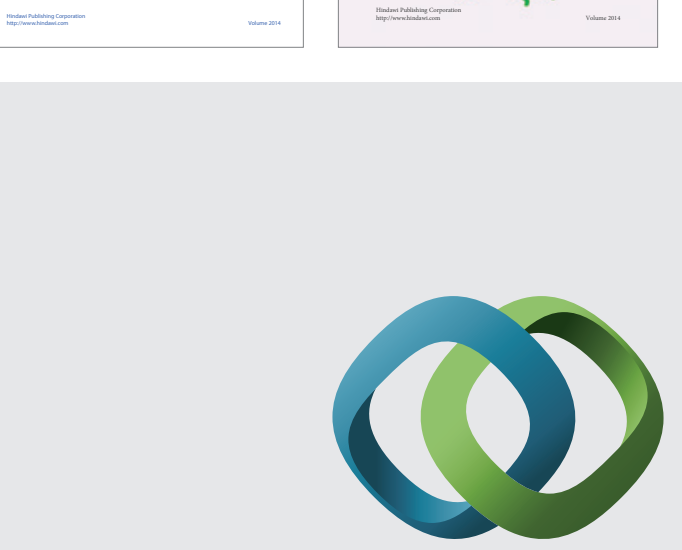

\section{Hindawi}

Submit your manuscripts at

http://www.hindawi.com
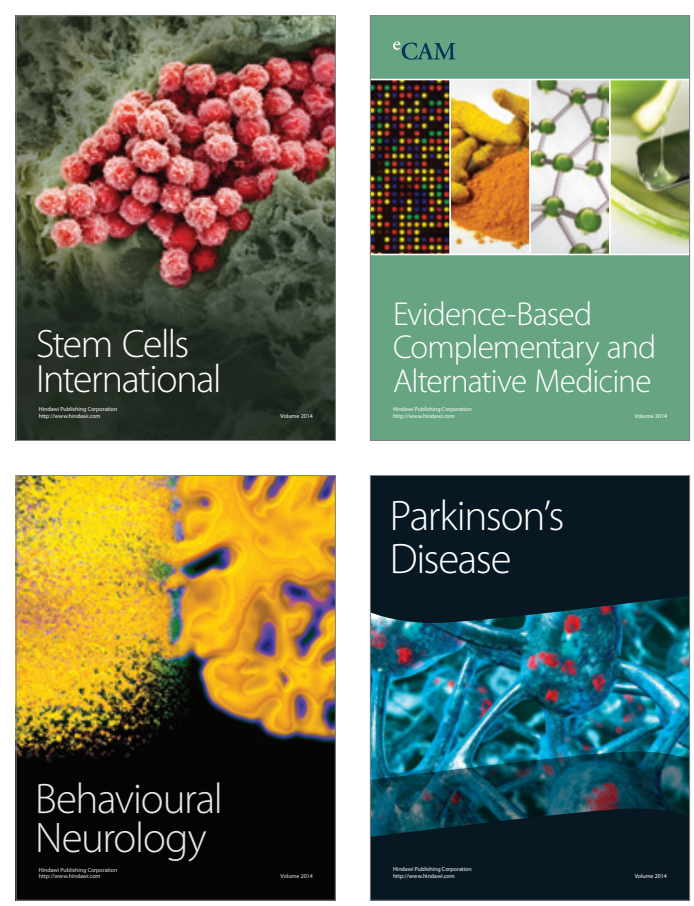

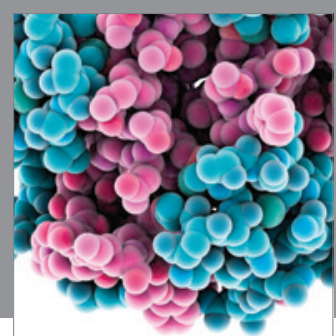

Journal of
Diabetes Research

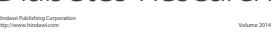

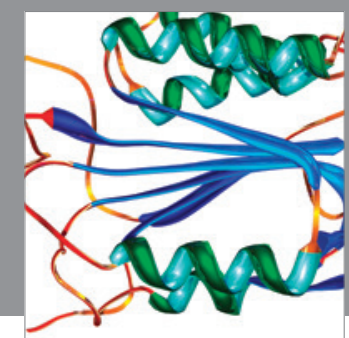

Disease Markers
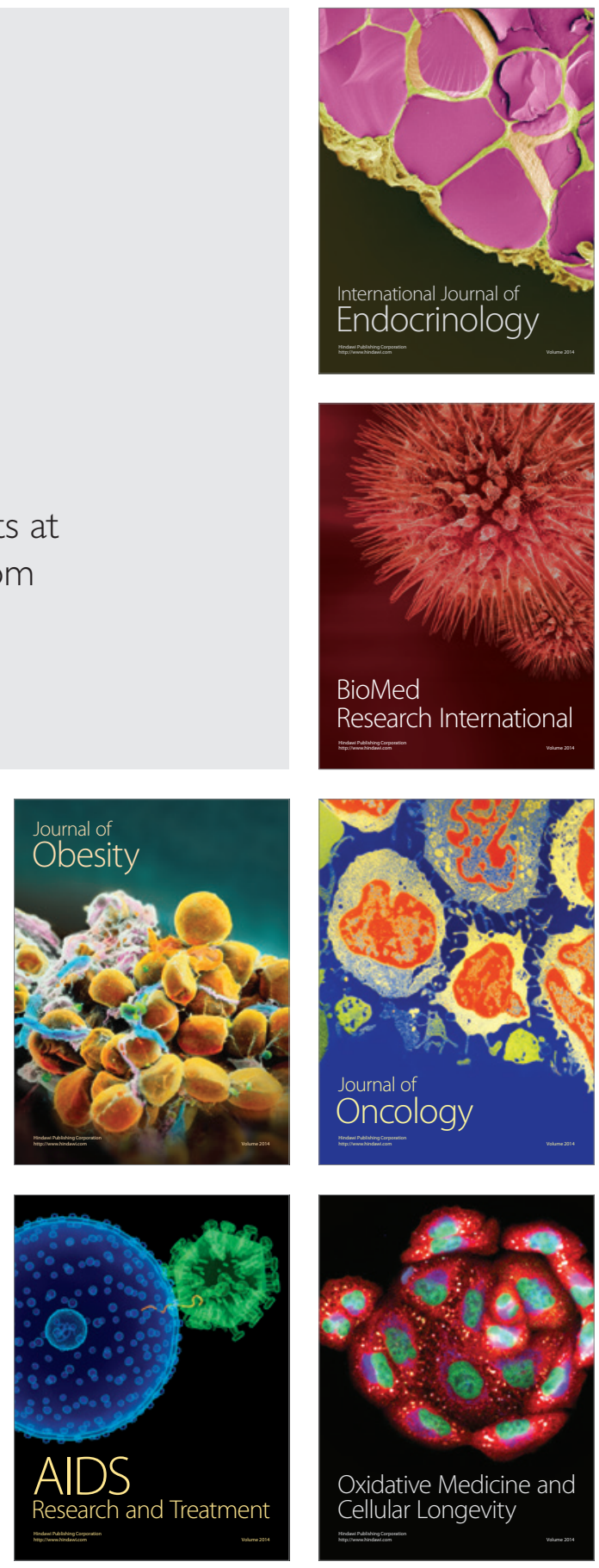